\title{
Methods to Link Climate Impacts and Regional Sustainability
}

\author{
Y. Y. Yin ${ }^{*}$ \\ AIRG, Environment Canada, and Sustainable Development Research Institute, University of British Columbia, 2029 West Mall, \\ Vancouver, BC V6T 1Z2, Canada
}

\begin{abstract}
This paper focuses on methodological development in research to study climate change impacts and regional sustainability. It starts with an introduction of a conceptual structure for identifying important attributes of regional sustainability and salient properties of climate change to guide research on regional impact assessment and adaptation options. This is followed by a brief review of some methods and approaches which have been used for climate impact assessment and policy evaluation. The paper then presents a research approach for climate change impact assessment and regional sustainability evaluation. In particular, an integrated approach is presented in some detail.
\end{abstract}

Keywords: Climate impact, sustainability, impact assessment

\section{Introduction}

There is an increasing concern about the effects of climatic change arising from human activity on agriculture, energy, transportation, tourism, and human health. The risk of global warming is so high that it could affect our planet's life-support-system. Developing countries, with a large portion of its economic product and population directly dependent on the natural resource sectors, are very vulnerable to climate change. In developing countries, the extremely limited land base and water resources have to provide a number of competing users with a range of different and often conflicting functions to meet their demands. While the demands for resources increase dramatically as population and economic grow, the availability and the inherent functions of natural resources are being reduced by climate change, land conversion, water pollution, and environmental degradation.

Developing countries need to design and apply advanced methods to deal with issues related to climate change and sustainable development. In this respect, international co-operative research is required to study the regional implications of climate change and variability for sustainable development. Such research will provide information on the sensitivity and adaptability of social and economic activities in order to aid decision making and to insure system sustainability.

The objective of an integrated climate change impact assessment is to study the implications of climate dynamics for sustainable regional development. To obtain a scientific understanding of the interactions between sustainable regional development and climate, integrated analytical meth-

\footnotetext{
*Corresponding author: yongyuan.yin@sdri.ubc.ca
}

ods is needed to provide holistic analysis of environmental dynamics and response policy. In particular, the analytical framework is capable of integrating major physical, biological, and socio-economic components of the region and can identify the regional economic-environmental impacts of climatic change. The paper will discuss linkages between impact assessment and decision making, and between climate change and sustainable development.

\section{Climate and Sustainable Regional Development}

Understanding the relationship between climate change impacts and sustainable regional development is a prerequisite for better decision making. This section presents a research structure for identifying the most important attributes of sustainability and the salient properties of climate variation and change to guide research on regional impact assessment and evaluation of adaptation options. It is suggested that once an understanding of climate related threats to sustainability is established, consideration of adaptation options can then follow. Adaptation options can be based on demonstrated strategies from the past or on identified opportunities relative to sensitive areas. Any adaptation strategy should then be evaluated according to the goals/ indicators of sustainability, such as economic viability, environmental maintenance, and social acceptability.

There are many definitions of sustainable development. In this paper, sustainable regional development (SRD) is broadly defined as the long-term use of regional resources which is economically viable, socially desirable, and environmentally non-degrading. Only those climatic phenomena which are relevant to $\mathrm{SRD}$ in a specific region are considered here.

IPCC Third Assessment Report (TAR) (2001) indicates that variations in climatic conditions combine with socio- 
economic forces to influence the nature of resource use systems, including impacts on the sustainability of regional development. Within each of the economic, social, and environmental sub-systems of a natural resource system, it is possible to evaluate sustainability according to such attributes as stability, resilience, flexibility or vulnerability. Applications of these principles are illustrated in Smit and Smithers (1993). Sustainability can be enhanced by adaptation, which makes the resource use system less vulnerable to climate dynamics.

The nature of climate dynamics and its relation to resource use systems has been studied for a long time. Properties of climate system (temperature, rainfall, etc.) for any region vary from year to year. Climate dynamics reflects forces which range in scale from the local to the solar system, and which operates over various time periods. These variations in climate systems are essentially uncertain, in the sense that it is not possible to predict with any certainty the conditions for next year. Climate usually refers to average or "normal" conditions, and climate dynamics deals mostly with changes in average conditions. In some years conditions deviate markedly from the average, and it is these extreme events that result in economic, environmental, and social impacts, losses and disasters via floods, droughts, dust storms, storm surges, and so on (Smit et al., 2000).

But disasters only occur if the human resource use system has not been improved to copying with such extreme events. Resource use systems, such as agriculture, settlements, forestry, transportation, can be managed to function successfully within a coping range. So long as climate conditions fall within this range the system can sustain. In other words, resource systems tend to be adaptive (and hence are sustainable) only within a limited range of climate conditions. It is often suggested that with increasing pressure on resources this coping range has become narrower over recent decades, thus exposing the system to increased climate-related risks (Burton, 1995). With climate dynamics, it is the frequency and magnitude of climate extremes relative to the coping range which are important for system sustainability. Systems with high adaptive capacity which can cope with the probability (not the certainty) of extreme events are not only more sustainable under the current climate regime, but will also be sustainable under changed climate regimes.

\section{Methodological Review}

The global environmental system is extremely complex with numerous heterogeneous components linked by various interactions or processes of a physical, chemical, biological, and socio-economic nature. The complex and dynamic nature of the global warming and SRD issue, thus, requires new analytical approaches to represent functions and interactions of a wide range of components of the Earth system. In order to adapt methods for climate impact analysis and option evaluation, it is important to understand the current development of methods and to appreciate their suit- ability in this research area. IPCC (1994) provides some guidelines for climate change impact assessment and option evaluation, and introduces a variety of methods which, however, are reviewed rather general. This paper attempts to provide more detailed pictures of these methods and their suitability for climate change impact study.

\subsection{Physical and Ecological Approach}

The physical and ecological approaches focus on different components and processes of the Earth system.

\subsubsection{Land Classification}

A traditional approach used in impact studies is to apply various classification methods. These include climate, vegetation, and land capability classification (LCC) (Koppen, 1936; Stamp, 1940; Holdridge, 1947). The main purpose of applying these classification schemes is to group regions into categories based on shared climate and other biophysical conditions. For example, LCC often differentiates units and sub-units on the basis of selected climatic, soil, morphological, and vegetative criteria.

The essence of applying classification methods for climate change impact study is based on the correlation between climate patterns and soil or vegetation distributions. In LCC, land capability patterns are determined by factors including climate, soil type, soil moisture and fertility, vegetation cover, topography, landform, and land degradation such as erosion and salinization (Goodchild, 1976). Changing of daily temperature and soil moisture conditions associated with global warming will shift the land capabilities for various uses. The results can then be used to show the impacts of climate change on land productivity. The classification approach can be used to estimate future physiographic changes as well as cropping patterns or migrations of forest tree species in response to rapid global warming. Then land capability classes under climate change conditions can be identified. Several classification methods were applied to study the shifting of the world crop distribution patterns (Emanuel et al., 1985; Leemans \& Solomon, 1993).

\subsubsection{Ecological Simulation Modelling}

Ecological simulation modelling is based on mathematical representations of the processes and interrelationships of ecosystems. Various simulation models have been used to examine the impacts of global warming on crop or tree productivity. These studies have indicated that crop or tree growth simulation models have considerable promise as tools for studying crop growth response to climate change for various regions (Wilks, 1988; Rosenzweig, 1985; Rosenberg, 1992; IPCC, 2001). The process-oriented or phenological simulation models which are commonly used by impact studies include: CERES wheat/maize (Jones et al., 1984), EPIC (Rosenberg, 1992), TAMW (Maas \& Arkin 1980), and Forest-BGC (Running et al., 1987).

Ecological simulation models can also be used to evaluate alternative adaptation options. For example, the adaptation options responding to changed climate in the models 
can be treated by allowing changes in new crop cultivars, tree species, or technologies more suitable for changed climate conditions (to build a new irrigation system).

Biological simulation modelling development usually focuses on the temporal aspect of ecological processes and ignores the spatial aspect. Another criticism of these models is their increasing size and complexity, which sets a barrier for many developing countries to conduct model validation and application for climate change impact study (WMO, 1984; WMO, 1986). One major shortcoming of these models is that they deterministically simulate plant growth on small spatial scales based on physical and biological factors and ignore the economic and technological factors. These models need extensive validation before being applied to other parts of the globe. Despite shortcomings, however, use of these simulation models in conjunction with GCM output and socio-economic models allows investigation of the impacts of climate change or adaptation options on various resource sectors.

\subsection{Social Impact Assessment Methods}

The purpose of social impact assessment (SIA) is to incorporate social values into the impact assessment of potential climate change or adaptation policies. To a large degree, SIA methods use traditional social science research methods such as surveying, interviewing, observation, and statistics. Stewart et al. (1992) applied these methods to find out the agreement and disagreement patterns of scientists on the global climate change issue.

Two other methods are alternative scenarios and Delphi techniques. The construction of future scenarios provides means to simulate future social conditions with some specific development projects. A Delphi is a much broader based technique which is based on experts' judgements. The final result of a Delphi is the refinement of guesses about the future, and reflects the mean opinion of experts. Changnon et al. (1992) used a Delphi method to identify the shifting perceptions of atmospheric scientists on the climate change issue. Modelling techniques have been adopted and applied in recent SIA studies. Yin and Cohen (1994) presented a systematic approach, assisted by questionnaire and analytic hierarchy process (AHP) methods to identify and specify regional policy concerns relating to climate change.

\subsection{Economic Impact Assessment Methods}

Many economic analysis methods have been used or proposed for climate change impact assessment or limitation option evaluation (Riebsame, 1988; Pearce, 1990; NAS, 1991). The two most widely used methods: cost-benefit analysis (CBA) and input-output analysis (IOA) are reviewed here.

\subsubsection{Cost-Benefit Analysis}

Cost-benefit analysis is the widely used method in economic impact assessment (Johansson, 1993). In climate change impact study, CBA can be applied for two broad purposes: (i) to assess the economic implications of climate change scenarios; and (ii) to evaluate response options subject to given global warming scenarios. Nordhaus (1992) applied CBA to estimate the effects of greenhouse gas (GHG) emission. His results indicated that the total cost of doubling $\mathrm{CO} 2$ would be only a few percent of gross domestic product (GDP).

The appropriateness of applying CBA for climate change impact analysis has been widely questioned (Smith \& Tirpak, 1989). In CBA, impacts on the economy, environment, or society are quantified in monetary value. All costs and benefits, including primary and higher order, are summed to derive an overall cost and benefit ratio which can then be used as a grand index to assess the economic efficiency of particular response options (Pearce \& Turner, 1990). Thompson (1990) suggested that methods which provide a 'final score' for various impacts should not be used as assessment tools because they may remove the responsibility for the decision from decision makers to analysts.

The underlying philosophy of CBA comes from the concept of potential Pareto improvement. Under this concept, a change is considered economically efficient if the gainers can compensate the losers (Randall, 1986). Obviously, CBA fails to take consideration of distribution effects among interest groups or among regions. In CBA, future benefit and cost flows are converted into present values by applying discount rates. Since discount rates are determined by the current generation, and since all future values are discounted, the technique is biased toward the current generation in economic impact analysis. Even Pearce (1990), an admirer of CBA, also has strong reservations about the appropriateness of CBA for climate change impact analysis.

The economic valuation techniques for assessing environmental or social impacts, either market-based or survey oriented (willingness to pay), are applied in CBA to convert any environmental and social effects into monetary terms. Application of economic valuation techniques to non-market goods and services in environmental and social systems creates many difficulties and problems. For example, major difficulties arise in putting a market price on wetland loss, landscape amenity, genetic diversity, irreversible resource depletion, human health damage or death, and other social impacts. Smith and Tirpak (1989) indicated that many decision makers do not feel comfortable with monetary estimates of values of lost human lives, environmental pollution, or endangered species.

\subsubsection{Input-Output Analysis (IOA)}

To identify the regional distribution of various impacts associated with global warming, the model structure should reflect the interactions between sectors and between regions. IOA provides such a framework for climate impact analysis. Every industrialized country now possesses a national-level input-output accounting framework. IOA has also achieved popularity in recent times as a useful tool in climate change related studies (Parry, 1987; Malone \& Yohe, 1992; Cohen, 1993). The main contributions of IOA is that it provides 
explicit supply and demand characteristics of individual economic sectors in different regions, and illustrates the nature of interrelationships among these economic sectors and between regions (Isard, 1960). Since the late 1960s, IOA has been extended to incorporate environmental factors into the economic input-output analysis (Miller \& Blair, 1985). Hickling Corporation Econometric Research Ltd. (1994) proposed an IOA approach to study the environmental impacts of climate change in Great Lakes Basin.

Despite the potential of economic-environmental input-output models in resource evaluation, applications of these models indicated that structural relationships between economic and environmental systems are not always appropriately integrated (O'Riordan \& Turner, 1983). In addition, the data requirements and the time for collecting the basic data for IOA are substantial. Pearce and Markandya (1989) indicate that the assumption of fixed coefficients of static production functions is one constraint on the power of IOA models for prediction purpose. This assumption is questionable when considering the long-term nature of climate change impact study because the whole economic structure will change in the future.

\subsection{Mathematical Programming Modelling}

Mathematical programming (MP) is an important approach in systems analysis to allow for simultaneous consideration of many factors and dimensions of various systems. MP can provide information for better decision making when choice among a set of feasible alternatives is required (Wagner, 1969; Chiang, 1984). Most existing programming models for environmental impact assessment are single objective and single sector linear programming (LP) models.

Brklacich and Smit (1992) applied a LP model to assess the effects of potential climate change scenarios on regional food production in Ontario. Mooney and Arthur (1987) employed a specific agricultural sector model to assess the effects of climate changes on the agricultural sector's behaviour as defined by production and employment levels, prices and incomes, and other variables. By using, however, single-objective and single-sector programming, LP was not flexible for identifying conflicts and trade-offs in integrated impact study. In this respect, multiple objective programming techniques have been developed. There are a number of diverse methods in multi-objective decision making (MODM). This paper focuses on goal programming (GP) modelling. Since integrated climate change impact assessment is characterised by multiple goals or criteria, a GP approach seems appropriate. The GP model can provide mechanisms to integrate various factors such as social, economic, and ecological. In integrated impact assessment, GP can deal with various pertinent objectives such as environmental quality, economic return, and energy conservation (Momero \& Rehman 1987). By adopting a systematic approach to identify goals, and by increasing computational runs and sensitivity analysis of parameters representing different preference ordering of goals, GP technique is effi- cient to find a satisfactory solution (Ignizio, 1982; Yin \& Pierce, 1993).

Conventional operation of GP model is to identify a satisfactory solution by minimizing the deviation from the goal targets or aspiration levels. The GP model developed in impact assessment, however, is applied in a different manner. The primary purpose of application of GP model in climate change study aims at impact assessment and scenario analysis.

Despite the potential in climate change impact assessment, the GP models are not without limitations. In the process of goal identification, ideally a set of well defined goals can be provided by the decision makers. In reality, however, neither analysts nor decision makers have a clear set of objectives with respect to dealing with climate change problems. Another major criticism of GP is its inability to account for many non-quantitative and intangible development goals.

\subsection{Systems Analysis and Integrated Approach}

Systems analysis provides decision makers with a research framework which can be used to involve the active participation of diverse groups/individuals from both the public and private sectors who attempt to share different perceptions of resource values, to co-ordinate and analyse a broad range of information, and to illuminate alternative courses of action and associated trade-offs. Both simulation modelling and other decision support modelling are parts of the systems analysis approach. Systems analysis is strategic, interactive, and that it includes multiple perspectives, which distinguishes it from most conventional analytical methods.

Integrated impact assessment approach, by its nature and complexity, must recognize and incorporate a number of factors and their interactions. An important aspect of integrated approach is the identification of consequences of alternative courses of action. How sensitive for example is the productivity of a resource system to climate change and, is the response to climate change acceptable from a policy perspective? To answer such questions requires the creation and application of appropriate evaluation systems to assess various climate change scenarios and to discover the implications of these scenarios and response options with respect to the attainment of sustainability goals. Three integrated assessment systems for climate change impact study are presented below for illustration purpose.

\subsubsection{IMAGE}

The Integrated Model to Assess the Greenhouse Effect (IMAGE) was originally developed by Jan Rotmans (1990), and was updated by Rotmans et al. (1994). IMAGE adopted a systems approach in designing a research framework to link modelling analysis with policy concerns for climate change impact study. IMAGE was later incorporated into an interactive computerized framework named the Evaluation of Strategies to address Climate change by Adapting to and Preventing Emissions (ESCAPE). ESCAPE was the result 
of a joint research efforts by the Climatic Research Unit at the University of East Anglia in U.K., the National Institute for Public Health and Environmental Protection of the Netherlands, the Environmental Change Unit at Oxford University in U.K., and the Environmental Resources Limited in U.K. Rotmans et al. (1994) applied the ESCAPE to study the impacts of climate change scenarios on several individual sectors, and to identify the implications of response policies for climate change. ESCAPE represents complicated factors, processes, and linkages of many systems influencing climate change. The approach, however, focuses on physical and chemical aspects, and deals with mainly limitation options at the global scale.

\subsubsection{The MINK Study}

A well known application of systems analysis approach to regional climate change impact assessment is the MINK study (USDOE, 1991). Resources for the Future (RFF) adapted a systems analysis approach to study the potential regional impacts of climate change and response options. The study covered four states: Missouri, Iowa, Nebraska, and Kansas (MINK). Estimates of the potential regional resource production and economic return under climate change scenarios were compared with those on present conditions to show regional economic impacts (Rosenberg, 1992). This approach provides a systematic assessment of the regional climate change impacts by using a sequential procedure which integrates various factors and brings together the potential climate change impacts and adaptation options.

\subsubsection{The Mackenzie Basin Impact Study (MBIS)}

The Mackenzie Basin Impact Study (MBIS) is a multi-year and multi-disciplinary research project to examine the regional impacts of projected global warming. MBIS was supported by the Government of Canada's Green Plan and other sponsors. The main purpose of the MBIS is to define the direction and magnitude of regional scale impacts of global warming scenarios on the physical, biological and human systems of the Mackenzie Basin. The study also identified regional policy implications of climate change (Cohen, 1997).

MBIS is an integrated regional impact assessment (IRIA) which is different from traditional sectoral studies. MBIS attempted to draw scientists, governments, and various public interests or stakeholders closer together to address common concerns for the Basin. MBIS is interdisciplinary and the questions addressed were inter-jurisdictional. A broad collaborative effort between government agencies, non-government organizations, and university researchers was established for the integrated impact assessment. The IRIA consists of 5-step for MBIS:

(1) The first step was to define the study area and the problem(s) of interest to that area.
(2) Major components of the Basin were determined based on their sensitivities to climate change. Linkages among components were established through workshops.

(3) A working committee (WC) was established at the beginning of the study. The WC is composed of representatives from collaborating government agencies and non-government stakeholders. Within the WC, an integration sub-committee was formed to link physical, biological, and social scientists, as well as representatives of regional interest groups.

(4) A set of climate and human scenarios were identified by the WC. The climate scenarios were derived mainly from climate model simulations and would be revisited later. The human scenarios include population growth and potential economic changes that were important to the Basin over the time period of the climate scenario.

(5) Substantial work had been completed by the WC to review and select research proposals, and to conduct workshops. Various projects were now under way to study the impacts of climate change on sensitive economic sectors of the Basin. Various analytical methods for studies of separate research projects dealing with the physical and biological components of the Mackenzie Basin Study were being applied for firstand second-order impact assessments.

More detailed discussion on MBIS can be found in Cohen (1997).

\subsection{Summary of the Methodological Review}

Various applications of assessment methodologies can be found in the literature of different disciplines. However, the majority of the applications focus either on physical, chemical, biological, or economic aspects of the Earth system. Applications which take a holistic viewpoint are relatively rare. Another important rigidity of these methods is that they often deal with one economic sector in isolation, failing to recognize the importance of intersectoral relations.

To obtain a scientific understanding of the interactions between sustainable development and climate change, integrated analytical methods are desirable. It is obvious that integrated impact assessment will never be achieved based on partial analyses of the total system. Integrated study requires a multidisciplinary and holistic approach to deal with the interrelations among the economic, ecological, and social systems. The introduction of systems analysis establishes a linkage between impact analysis and decision making. It appears that the systems analysis approach can be used as a guide in designing an integrated research framework to undertake climate change impact assessment. Systems analysis approach is consistent with the general guidelines proposed by IPCC (1994) for conducting climate change impact analysis and adaptation option evaluation. 


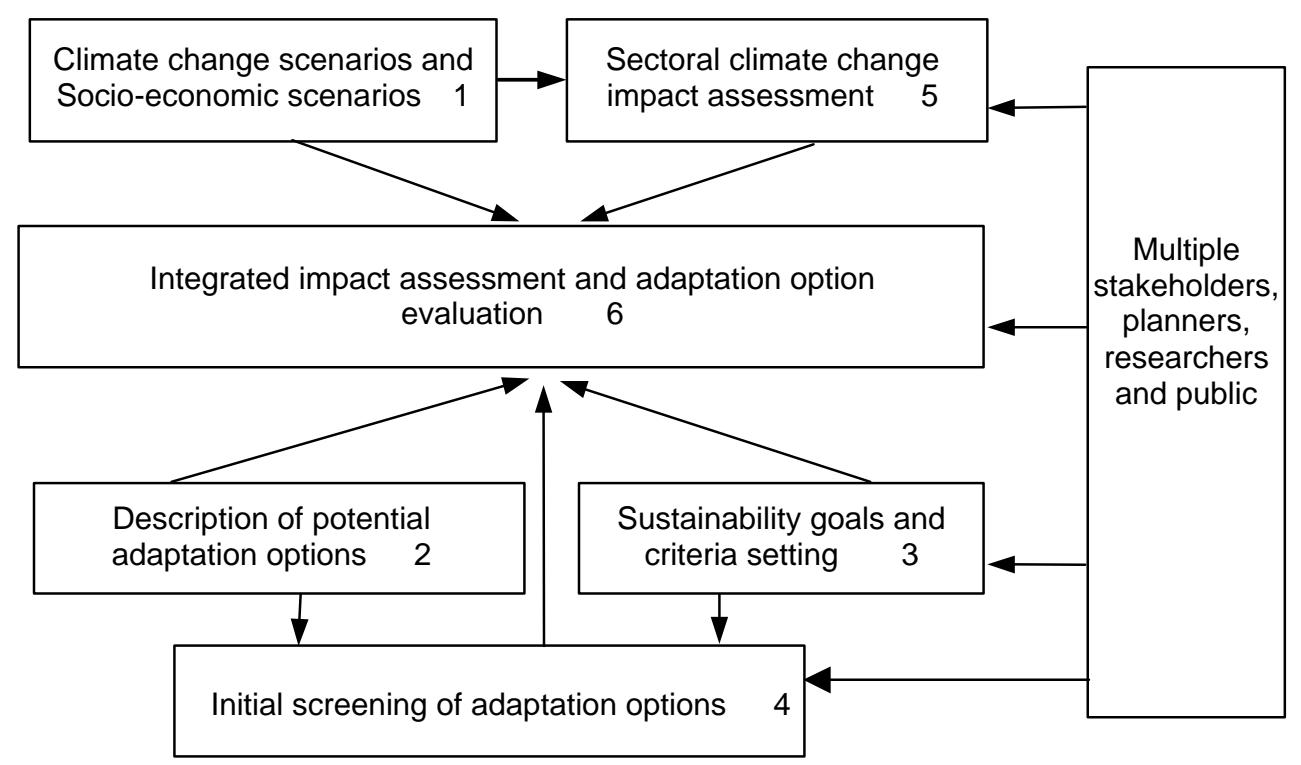

Figure 1. The general framework of the integrated assessment approach.

\section{Methods Used for the Integrated Approach}

The introduction of the research structure in section 2 for identifying the most important attributes of SRD and the salient properties of climate dynamics to guide a program on regional impact assessment and evaluation of adaptation options establishes a linkage between impact analysis and decision making. An integrated research framework is designed to link climate change impact assessment and sustainability evaluation.

\subsection{The General Research Approach}

Figure 1 presents the proposed research approach which consists of the six main components: (1) define problems; (2) description of potential adaptation options; (3) goal or criteria setting; (4) initial screening of options; (5) climate change impact assessment; and (6) integrated impact assessment and adaptation option evaluation. This section presents some methods or techniques that have the potential to be used for the integrated approach.

\subsection{Identifying Goals by AHP}

The analytic hierarchy process (AHP) developed by Saaty (1980), a multi-criteria decision making (MCDM) technique, can be used to identify goals and their priorities. The identification of assessment goals, criteria, and endpoints is necessary to ensure that the outputs of this study reflect major concerns of various stakeholders in the region. Thus, the approach provides means to link policy concerns with scientific results of global climate change research. In the analysis, goals are used as evaluation criteria by which the effects of climate change or/and the efficiency of alternative adaptation options, in terms of progression toward or regression from these goals, can be measured.

To assist decision makers in making judgement on goal priority involving multiple criteria, the AHP can provide means by which alternative goals could be compared and evaluated in an orderly and systematic manner. Literature in management science and operations research has indicated that AHP technique is appropriate and even better than other weighting method in multi-objective decision making involving subjective information (Yager, 1979; Anderson et al., 1986).

The AHP requires the decision makers to provide judgements on the relative importance of each of the goals. The result of the AHP is a prioritized ranking indicating the overall preference for each of the goals. Another feature of the AHP is that it provides a flexible framework for public participation in decision making or problem solving. In AHP exercise, a decision maker compares goals two at a time, which is termed pairwise comparison. The AHP employs an underlying scale with values from 1 to 9 to score the relative preferences for two items (Saaty, 1982). It should be noted that the scores selected represent linguistic responses and are not strict mathematical ratios. The scores can be determined with qualitative and subjective information. These values will be used as input for the next step of AHP, which is to construct a pairwise comparison matrix.

In complex decision making involving uncertainty, inconsistency in making judgement is a common problem. To ensure that the judgements made by decision makers are logical and reasonable, information about whether the pairwise comparisons are consistent is needed. AHP provides additional information on the consistency of judgement 
inherent in the pairwise comparison process. For example, if goal 1 is considered better than goal 2 , goal 2 is better than goal 3, but goal 3 is better than 1, the judgement is inconsistent. The values of the inconsistency ratio are determined by the maximum eigenvalue of the matrix (Palmer \& Lund, 1986). A detailed application of the AHP method in regional climate change impact assessment was conducted by Yin and Cohen (1984).

\subsection{Scenario Development from GCM and Other Meth- ods}

One of the distinctive features of the research framework is the emphasis placed on design of meaningful scenarios representing different future conditions. Assessing the implications of different response options, policies, or climate change for achieving sustainable regional development is as much an art as it is a science. This situation exists because of uncertainties over future conditions such as the magnitude of warming, the time of climate change, the impacts of climate change, and other factors such as future societal demand associated with population growth and income increase, economic development, and technological change. In response to these uncertainties, scenarios can be created to represent alternative future conditions. In this study, three types of scenarios will be specified: climate change, future socio-economic conditions, and response options.

One essential step in scenario evaluation is the identification of possible response options to deal with climate change impacts. Since the options possess different characteristics, implementing them would have various impacts on different locations and on different goal achievements. Each option may cause both positive and negative impacts. For example, a new irrigation system may reduce negative impacts on crop yield, but may also create negative impacts on the water balance goal.

According to the Tinbergen principle, in order to achieve a desirable outcome, it is necessary to design as many options or policies as there are objectives (Harvey \& Whitby, 1988). In an analogous manner the number of scenarios required in impact studies will be directly related to the issues or policies requiring investigation. Thus the number of response option scenarios required for this study depends on how many adaptation/limitation alternatives or options need to be investigated.

\subsection{Impacts Identification by FPR Method and Simula- tion Modelling}

\subsubsection{Impact Assessment by FPR}

The fuzzy pattern recognition (FPR) method can be employed to illustrate future land use patterns in response to rapid global warming. Land capability classes under climate change conditions can also be identified. Considering the large number of factors and land uses involved in the land capability classification (LCC), and the qualitative nature of some aspects, FPR is appropriate to perform the mathematical classification of land use pattern and land capability.
Data on current climate and climate change scenarios will be used to indicate the potential shifts of regional land use pattern. The fuzzy results will also identify the changes of land capabilities for various uses including agriculture, forest, wildlife, and others by using all the numbers in a fuzzy result set.

The essence of applying fuzzy pattern recognition for climate change impact study is based on the correlation between climate patterns and soil or vegetation distributions. In LCC, land capability patterns are determined by factors including climate, soil type, soil moisture and fertility, vegetation cover, topography, landform, and land degradation such as erosion and salinization (Goodchild, 1976). Changing of daily temperature and soil moisture conditions associated with global warming will shift the land capabilities for various uses. The results can then be used to show the impacts of climate change on land productivity.

Specifically, the classification approach employed involving two steps. First, a biophysical classification scheme will be used to correlate climate variables and vegetation patterns. This step will identify the changing regional vegetation distribution patterns under global warming scenarios. The classification scheme will first be tested against historical data. Secondly, a more comprehensive classification scheme will be developed to indicate the changing spatial patterns of land capability classes under climate change conditions. The attributes incorporated in this land capability classification scheme include climate, soil moisture and fertility, landform, vegetation, topography, erosion, and other factors.

\subsubsection{Impact Assessment by Simulation}

While simulation models are different in terms of the mathematical structures and variables selected, they are common in using mathematical equations to simulate certain physical, chemical, and biological processes. These models usually are composed of several sub-models representing processes of weather, hydrology, nutrient, erosion, plant or tree growth, and plant environment. The purpose of these simulations is to identify the future state of the ecosystems associated with climate change conditions. For example, a number of different types of simulation models have been designed to study crop or tree growth response to climate change (IPCC, 1994).

Since crop or tree growth sub-models are often coupled with atmospheric and hydrologic sub-models, it is obvious that links between crop or tree development and climate change can be established. Climate data reflecting alternative scenarios can be used as inputs to the crop or tree growth models. By proceeding in this manner through a series of scenarios, it is possible to evaluate whether climate changes that will occur are accommodated by declining or increasing crop or tree yields.

Ecological simulation models can also be used to evaluate alternative adaptation options. For example, the adaptation of certain measures to respond changed climate in the models can be treated by allowing changes in new crop 
cultivars, tree species, or technologies more suitable for changed climate conditions. The sensitivity of forest- or agro-ecosystems to changes in hydrologic regimes as a result of irrigation development can be represented by the model. By incorporating changes to certain parameters, the model results will show the effects of adaptation options on crop or tree yields associated with changed climate. Information on the various impacts of scenarios will be compiled into impact matrices for option evaluation.

\subsection{The Integrated Assessment System}

An integrated assessment (IA) system can be designed for climate change impact assessment and policy evaluation. The integrated system may employ advanced analytical techniques including goal programming (GP), AHP, FPR, and/or neural network (NN) which is a specific artificial intelligence (AI) technique. These techniques may be applied to identify the implications of climate change scenarios for sustainable regional development. Desirable adaptation options to deal with climate change impacts can be identified through the multi-criteria evaluation process.

Considering the fact that in multi-objective decision making not all the objectives can be optimized, GP attempts to find a solution which comes as close as possible to the satisfaction of various goals (Nijkamp \& Spronk 1979). Application of GP in this study will emphasize "bottom-up" decision process and the inclusion of various interest groups, private and public sectors, and different levels of government.

The procedure of the integrated assessment is to translate climatic change and/or adaptation policies into specific analytical questions that can be addressed by the model. Climatic change or response policies will influence resource production, resource availability and suitability for each sector, demands for resource products, greenhouse gas emission reduction and soil erosion rates control, and other factors affecting sustainability of the region. In the assessment process, different scenarios are represented in the structure of the GP model by modifying parameters in the coefficient matrix, the right-hand-side (RHS) vector, and the objective function.

In order to assess the impacts of different adaptation options on regional sustainability, a base scenario reflecting 'business as usual' conditions of the region is usually created for comparison. Alternative scenarios can then be created to reflect conditions coupled with a specific adaptation option to deal with climatic change impacts. The adaptation impacts are the difference between status quo scenario and the adaptation scenario.

The multi-goal evaluation process will take consideration of stakeholder's preference of goals derived from previous AHP analysis in determining what constitutes a favourable option or policy and what is unacceptable. The GP model is able to meet both the participatory needs of the study and to explicitly treat the values (goal preference) which are used to determine the merits of alternative courses of action. Several algorithmic techniques can be adopted to solve GP models.

\section{Conclusions}

The preceding discussion has illustrated an integrated climate change impact assessment approach and several potential methods which can be employed to form the integrated approach for integrated climate change assessment and sustainable policy evaluation. More detailed discussion on major techniques employed to form the integrated approach can be found in other articles (Yin et al., 2000, 2003; Yin, 2001). These research methods have been tested to some extent in above mentioned articles. The integrated approach presented here provides an introduction to incorporating scenario specification, AHP, simulation modelling, GP, and other technologies to examine the implications of climate change for regional sustainable development. The approach is flexible enough to incorporate other methods for improvement.

\section{References}

Anderson, D.R., Sweeney, D.J. and Williams, T.A. (1986). Quantitative Methods for Business, 3rd Edition, St. Paul, West Publishing Company, MN, USA.

Burton, I. (1995). Adaptation to climate change and variability: an approach through empirical research, in Y.Y. Yin, M. Sanderson and G. Tian (Eds.), Climate Change Impact Assessment and Adaptation Option Evaluation: Chinese and Canadian Perspectives, Beijing, China.

Brklacich, M. and Smit, B. (1992). Implications of changes in climatic averages and variability on food production opportunities in Ontario, Canada. Clim. Change, 20(1), 1-20.

Changnon, S.A., Wendland, W.M. and Changnon, J.M. (1992). Shifts in perceptions of climate change: A delphi experiment revisited. Bull. Am. Meteorol. Soc., 73(10), 1623-1627.

Chiang, A.C. (1984). Fundamental Methods of Mathematical Economics, McGraw-Hall, New York, NY, USA.

Cohen, S.J. (Ed.) (1993). Mackenzie Basin Impact Study Interim Report \#1, Environment Canada, Edmonton, Alberta, Canada.

Cohen, S.J. (1997). Mackenzie Basin Impact Study (MBIS), Final Report, Environment Canada, Downsview, Ontario, Canada.

Emanuel, W.R., Shugart, H.H. and Stevenson, M.P. (1985). Climate change and the broad-scale distribution of terrestrial ecosystem complexes. Clim. Change, 7, 29-43.

Goodchild, M.F. (1976). The Determinants of Land Capability, Lands Directorate, Environment Canada, Ottawa, Canada.

Harvey, D. and Whitby, M. (1988). Issues and policy, in M. Whitby and J. Olerenshaw (Eds.), Land Use and the European Environment, Bellhaven Press, London.

Hickling Corporation Econometric Research Ltd. (1994). LINK, An Environment-Economy Framework for Assessing the Economic Impacts of Climate Change on the Ontario Economy, Final Report for Atmospheric Environment Service, Environment Canada, Toronto, Canada.

Holdridge, L.R. (1947). Determination of world plant formations from simple climatic data. Science, 105, 367-368.

Ignizio, J.P. (1982). Linear Programming in Single- \& Multiple-Objective Systems, Prentice Hall, Englewood Cliffs, NJ, USA.

IPCC (1994). IPCC Technical Guidelines for Assessing Climate 
Change Impacts and Adaptations, Working Group II of the Intergovernmental Panel on climate Change, University College London, UK.

IPCC (2001). Climate Change 2001: The Scientific Basis, Working Group I of the Intergovernmental Panel on Climate Change.

IPCC (2001). Climate Change 2001: Impacts, Adaptation, and Vulnerability, Summary for Policymakers, Working Group II of the Intergovernmental Panel on Climate Change. Geneva, Switzerland.

Isard, W. (1960). Methods of Regional Analysis: An Introduction to Regional Science, MIT Press, Cambridge, Boston, MA, USA.

Johansson, P. (1993). Cost-Benefit Analysis of Environmental Change, Cambridge University Press, Cambridge, UK.

Jones, C.A., Ritchie, J.T., Kiniry, J.R., Godwin, D.C. and Otter, S.I. (1984). The CERES wheat and maize models, in Proc. of the International Symposium on Minimum Data Sets for Agrotechnology Transfer, ICRISAT Center, India.

Koppen, W. (1936). Das Geographische Support system der Klimate, in W. Koppen and R. Geiger (Eds.), Handbuch der Klimatologie, Berlin, Gebruder Borntrager.

Leemans, R. and Solomon, A.M. (1993). Modelling the potential change in yield and distribution of the Earth's crops under a warmed climate. Clim. Res., 3, 79-96.

Malone, T. and Yohe, G. (1992). Towards a general method for analysis regional impacts of global change. Global Environ. Change, 2(2), 101-110.

Maas, S.J. and Arkin, G.F. (1980). TAMW: A Wheat Growth and Development Simulation Model, Program and Model Documentation No. 80-3, Blackland Research Center, Texas Agricultural Experiment Station, Temple, TX, USA.

Miller, R.E. and Blair, P.D. (1985). Input-Output Analysis: Foundations and Extensions, Prentice Hall, Englewood Cliffs, NJ, USA.

Mooney, S. and Arthur, L.M. (1990). The impacts of climate change on agriculture in Manitoba. Can. J. Agric. Econ., 38, 685-694.

NAS (1991). Policy Implications of Greenhouse Warming, National Academy Press, Washington, DC, USA.

Nijkamp, P.P. and Spronk, J. (1979). Interactive multiple goal programming: an evaluation and some results, in G. Fandel and T. Gal (Eds.), Proc. of the Third Conference Hagen/Konigswinter, West Germany, Multiple Criteria Decision Making Theory and Application, Springer-Verlag, Berlin.

Nordhaus, W. (1992). An optimal path for controlling greenhouse gases. Sciences, 258, 1315.

O'Riordan, T. and Turner, K. (Eds.) (1983). An Annotated Reader in Environmental Planning and Management, Pergamon Press Ltd., Oxford, England.

Palmer, R.N. and Lund, J.R. (1986). Multi-objective analysis with subjective information. J. Water Resour. Plann. Manage., 111(4), 399-416.

Parry, M.L., Carter, T.R. and Konijn, N.T. (Eds.) (1987). An Assessment of Climatic Variations on Agriculture, Volume I, Assessment in Cool Temperate and Cold Regions, Volume II, Assessments in Semi-Arid Regions, Reidel, Dordrecht, Netherlands.

Pearce, D. and Markandya, A. (1989). The Greenhouse Effect, Climatic Change and Sea Levels: an Overview, Climate Research Unit, University of East Anglia, UK.

Pearce, D. (1990). Methodological Guidelines for Assessing the Socio-Economic Impacts of Climate Change, Environment Directorate, OECD.

Pearce, D. and Turner, R.K. (1990). Economics of Natural Resources and the Environment, Harvester Wheatsheaf, New York, NY, USA.

Riebsame, W.E. (1988). Assessing the Social Implications of Climate Fluctuations: A Guide to Climate Impact Studies, United
Nations Environment Programme, Nairobi.

Randall, A. (1986). Valuation in a policy context, in D.W. Bromley (Ed.), Natural Resource Economics: Policy Problems and Contemporary Analysis, Kluwer-Nifhoff Publishing, Boston, MA, USA.

Romero, C. and Rehman, T. (1987). Natural resource management and the use of multiple criteria decision-making techniques: a review. Eur. Rev. Agric. Econ., 14, 061-089.

Rosenberg, N.J. (Guest Editor) (1992). A Methodology for Assessing Regional Agricultural Consequences of Climate Change: Application to the MINK Region. Agric. For. Meteorol., 59(1-2).

Rosenzweig, C. (1985). Potential $\mathrm{CO}_{2}$ - induced climate effects on North American wheat-producing regions. Clim. Change, 7, 367-389.

Rotmans, J. (1990). IMAGE: An Integrated Model to Assess the Greenhouse Effect, Kluwer Academic Publishers, Dordrecht, Netherlands.

Rotmans, J., Hulme, M. and Downing, T. (1994). Climate change implications for Europe: An application of the ESCAPE model. Global Environ. Change, 4(2), 97-124.

Running, S.W., Nemani, R. and Hungerford, R.D. (1987). Extrapolation of synoptic meteorological data in mountainous terrain and its use for simulating forest evapotranspiration and photosynthesis. Can. J. For. Res., 17, 472-483.

Saaty, T.L. (1980). The Analytic Hierarchy Process, McGraw-Hall, New York, NY, USA.

Saaty, T.L. (1982). Decision Making for Leaders: The Analytical Hierarchy Process for Decisions in a Complex World, McGraw-Hall, New York, NY, USA.

Smit, B. and Smithers, J. (1993). Sustainable agriculture: interpretations, analyses and prospects. Can. J. Reg. Sci., 16(3), 399-524.

Smit, B., Burton, I., Klein, R.J.T. and Wandel, J. (2000). An anatomy of adaptation to climate change and variability. Clim. Change, 45, 223-251.

Smith, J.B. and Tirpak, D. (Eds.) (1989). The Potential Effects of Global Climate Change on the United States, Report to Congress, EPA.

Stamp, D. (1940). Fertility, productivity and classification of land in Britain. Geogr. J., 96, 389-412.

Stewart, T.R., Mumpower, J.L. and Reagan-Cirincone, P. (1992). Scientists' Agreement and Disagreement about Global Climate Change: Evidence from Surveys, Research report, Center for Policy Research, State University of New York, Albany, NY, USA.

Thompson, M.A. (1990). Determining impact significance in EIA: A review of 24 methodologies. J. Environ. Manage., 30, 235-250

Thornthwaite, C.W. (1948). An approach toward a rational classification of climate. Geogr. Rev., 38, 55-94.

USDOE (1991). Processes for Identifying Regional Influences of and Responses to Increasing Atmospheric $\mathrm{CO}_{2}$ and Climate Change - The MINK Project, United States Department of Energy, Washington, DC, USA.

Wagner, H.M. (1969). Principle of Operations Research, Prentice Hall, Englewood Cliffs, NJ, USA.

Wilks, D.S. (1988). Climatic change on North American grain agriculture using general circulation model information. Clim. Change, 13, 19-42

WMO (1984). Report of the WMO/UNEP/ICSU-SCOPE Expert Meeting on the Reliability of Crop-Climate Models for Assessing the Impacts of Climate Change and Variability, WCP-90, World Meteorological Organization, Geneva.

WMO (1986). Summary Analysis of the Responses to the WMO 
Questionnaire on Crop-Climate Models, WCP-90 (Part II), World Meteorological Organization, Geneva.

Yager, R.R. (1979). An eigenvalue method of obtaining subjective probabilities. Behav. Sci., 24, 382-387.

Yin, Y.Y. and Pierce, J.T. (1993). Integrated resource assessment and sustainable land use. Environ. Manage., 17(3), 319-327.

Yin, Y.Y. and Cohen, S. (1994). Identifying regional policy concerns associated with global climate change. Global Environ. Change, 4(3), 245-260.

Yin, Y.Y., Cohen, S. and Huang, G.H. (2000). Global climate change and regional sustainable development: the case of Mackenzie Basin in Canada. Integr. Assess. 1, 21-36.

Yin, Y.Y. (2001). Designing an Integrated Approach for Evaluating Adaptation Options to Reduce Climate Change Vulnerability in the Georgia Basin, Final Report Submitted to Adaptation Liaison Office, Climate Change Action Fund, Ottawa, Canada.

Yin, Y.Y., Miao, Q. and Tian, G. (Eds.) (2003). Climate Change and Regional Sustainable Development: A Case in the Changjiang Region of China, Sciences Press, Beijing and New York. 